\title{
Blood Indices in Patients with Androgenetic Alopecia
}

A.I.El-Taweel ${ }^{1}$, A.I.Mustafa ${ }^{1}$, W.A.Abd El-Halim ${ }^{2}$ and A.A.Roshdy ${ }^{3}$

${ }^{1}$ Dermatology, Venereology and Andrology Dept., Faculty of Medicine, Benha Univ., Benha, Egypt

${ }^{2}$ Clinical and Chemical Pathology Dept., Faculty of Medicine, Benha Univ., Benha, Egypt

${ }^{3}$ Dermatology, Venereology and Andrology, Dept., Faculty of Medicine, Zagazig Univ., Zagazig, Egypt

E-Mail:amira@gmail.com

\begin{abstract}
Hair is a marvelous structure with cosmetic function. Androgenetic alopecia [AGA] is the most common hair loss condition affects both sexes; AGA is thinning of scalp hairs that initiated by androgens in susceptible patients. Complete blood count [CBC] parameters have been introduced as diagnostic biomarkers for many diseases associated with the inflammatory process: This study aimed to assess blood indices in patients with androgenetic alopecia. This case control study was included thirty male and twenty female patients complaining of androgenetic alopecia, and thirty age and BMI matched healthy volunteers. Patients were recruited from outpatient clinic of Dermatology, Venereology and Andrology Department of Benha University Hospitals during the period from December 2018 to June 2019.All participants were tested for determination of blood indices. Results: PLT count was found to lower in AGA patients compared to controls without significant difference. AGA group showed significantly higher MPV, NLR and PLR were found to be significantly higher in AGA patients compared to controls. Patients with AGA showed high level NLR, PLR and MPV.
\end{abstract}

Key words: Androgenetic alopecia, Blood indices, Diagnosis.

\section{Introduction}

Hair is a marvelous structure with cosmetic function. Androgenetic alopecia [AGA] is the most common hair loss condition affects both sexes; AGA is thinning of scalp hairs that initiated by androgens in susceptible patients [1].

The onset of AGA mostly in late adolescence, gradual and slowly develops over years. The frequency and the grade of severity of AGA increases with age. Up to $30 \%$ of males will have AGA by 30 years, $50 \%$ by 50 years, and $80 \%$ by 70 years [2].

Complete blood count [CBC] parameters have been introduced as diagnostic biomarkers for many diseases associated with the inflammatory process: Red cell distribution width [RDW] demonstrates the size variability of circulating erythrocytes and is calculated by dividing the standard deviation of red blood cell [RBC] volume by mean corpuscular volume $[\mathrm{MCV}]$ and is used to identify the causes of anemia [3].

Mean platelet volume [MPV] has been identified as a platelet activation marker and plays an important role in inflammatory reactions [4] .

Among the other parameters, the ratio of neutrophils to lymphocytes [NLR] and the ratio of platelets to lymphocytes [PLR] are simple markers of systemic inflammatory response [5].

Recently, these markers have been studied, individually or together, in relation to various dermatologic diseases such as psoriasis, rheumatologic diseases of dermatology, cutaneous vasculitis, atopic eczema, pityriasis rosea, Behçet's disease, recurrent aphthous stomatitis, and pemphigus vulgaris [6].

There are no studies that investigate the relationship between androgenetic alopecia and these inflammatory markers, and to the best of our knowledge, this is the first study to examine the association between these markers and disease severity.

The study aimed to assess blood indices in patients with androgenetic alopecia.

\section{Patients and methods 2.1Patients}

This case control study was included thirty male and twenty female patients complaining of androgenetic alopecia, and thirty age and BMI matched healthy volunteers. Patients were recruited from outpatient clinic of Dermatology, Venereology and Andrology Department of Benha University Hospitals during the period from December 2018 to June 2019.

\subsubsection{Inclusion criteria}

The inclusion criteria for patients with AGA were: being over 18 years of age, and being willing to participate in the study.

\section{2..1.2Administrative Design}

This study was approved by the research ethical committee of Benha Faculty of Medicine.

\subsubsection{Ethical consideration}


Before taking blood samples, a written informed consent was taken from each subject included in the current study.

\section{All participants were divided into two groups}

- Group A: thirty male and twenty female patients with an AGA.

- Group B: thirty age and BMI matched healthy volunteers as controls group.

\subsection{Methods}

All patients were subjected to the following

Full history taking

\subsubsection{Clinical Examination}

- Measure of the body height and weight to calculate the body mass index

\subsubsection{Laboratory investigations}

All participants were tested for determination of blood indices.

Sample analysis complete blood picture was performed on system XN cell counter [System Corporation, Japan].

The following parameters were recorded:

Platelets count.

1- Absolute lymphocyte count.

2- Absolute neutrophils count.

3- Mean platelet volume [MPV] .

In addition, the following ratios were calculated from previous results:

1- Neutrophil/ Lymphocyte [N/L] ratio=absolute neutrophils count/ absolute lymphocyte count.
2- Platelet/ Lymphocyte [P/L] ratio=platelet count/absolute lymphocyte count.

\subsection{Statistical analysis}

The collected data was revised, coded, tabulated and introduced to a PC using Statistical package for Social Science [IBM Corp. Released 2011. IBM SPSS Statistics for Windows, Version 20.0. Armonk, NY: IBM Corp.]. Data were presented and suitable analysis was done according to the type of data obtained for each parameter.

\section{Descriptive statistics}

Mean Standard deviation $[ \pm$ SD] for numerical data. Frequency and percentage of non-numerical data.

\section{Analytical statistics}

Student T Test was used to assess the statistical significance of the difference between two study group means. Chi-Square test was used to examine the relationship between two qualitative variables. N.B: $p$ is significant if $<0.05$ at confidence interval $95 \%$.

\section{Results}

The mean age of AGA patients was 36.6 years. Male patients represented $60 \%$, while females represented $40 \%$. In addition to 30 healthy control subjects of matched age and gender.BMI did not differ significantly between both groups, $[\mathrm{P}$ value $=0.562]$.Patients with AGA showed significantly higher NLR, PLR and MPV when compared to control group [ $<00.001$ for each] as showen in Table [ $1]$.

Table [1] Sociodemographic data and blood indices of both studied groups.

\begin{tabular}{|c|c|c|c|c|c|c|}
\hline \multirow[b]{2}{*}{ Age [years] } & \multirow[b]{2}{*}{ Mean \pm SD } & \multicolumn{2}{|c|}{$\begin{array}{c}\text { Control group } \\
\mathbf{N}=\mathbf{3 0}\end{array}$} & \multicolumn{2}{|c|}{$\begin{array}{c}\text { Patients group AGA } \\
\mathbf{N}=\mathbf{5 0}\end{array}$} & \multirow{2}{*}{$\begin{array}{c}\text { P-value } \\
0.826^{\mathrm{T}}\end{array}$} \\
\hline & & 36.1 & 9.5 & 36.6 & 9.3 & \\
\hline Male & $\mathrm{N}, \%$ & 15 & $50 \%$ & 30 & $60.0 \%$ & $0.373^{\mathrm{C}}$ \\
\hline Female & $\mathrm{N}, \%$ & 15 & $50 \%$ & 20 & $40.0 \%$ & \\
\hline BMI $\left[\mathrm{kg} / \mathrm{m}^{2}\right]$ & Mean \pm SD & 24.2 & 2.8 & 24.5 & 2.7 & $0.552^{\mathrm{T}}$ \\
\hline Normal weight & $\mathrm{N}, \%$ & 17 & $56.7 \%$ & 26 & $52.0 \%$ & $0.685^{\mathrm{C}}$ \\
\hline Over weight & $\mathrm{N}, \%$ & 13 & $43.3 \%$ & 24 & $48.0 \%$ & \\
\hline NLR & Mean \pm SD & \multicolumn{2}{|c|}{$1.1 \pm 0.3$} & \multicolumn{2}{|c|}{$2.2 \pm 0.7$} & $<0.002^{\mathrm{T}}$ \\
\hline PLR & Mean \pm SD & \multicolumn{2}{|c|}{$70.8 \pm 20.3$} & \multicolumn{2}{|c|}{$131.3 \pm 44.4$} & $<0.001^{\mathrm{T}}$ \\
\hline Platelets $\left[\times 10^{9} / \mathrm{L}\right]$ & Mean \pm SD & \multicolumn{2}{|c|}{$262.5 \pm 82.0$} & \multicolumn{2}{|c|}{$254.2 \pm 53.7$} & $0.574^{\mathrm{T}}$ \\
\hline MPV [fL] & Mean \pm SD & \multicolumn{2}{|c|}{$8.0 \pm 0.7$} & \multicolumn{2}{|c|}{$9.6 \pm 0.8$} & $<0.011^{\mathrm{T}}$ \\
\hline
\end{tabular}

SD, standard deviation; T, Student t test; C, chi square.

\section{Discussion}

This study showed that, there was no statistical significant difference found between the two groups regarding sex. There was a male predominance of [60\%] of the cases.This agrees with [7] who found that in a population-based study in India of 1005 participants showed 58\% AGA in males. 
In the present work, the mean the age of the AGA patients was $36.6 \pm 9.3$ years for the cases and $36.1 \pm 9.5$ years for the controls with no statistical significant difference noted between the two groups. These findings were in consistence with [8] who found that, there was no statistical significant difference between the two groups regarding age.

This study showed that, BMI was comparable in the two groups; there was $48 \%$ of the studied AGA patients were overweight. This agrees with [9] demonstrated higher BMI in men with alopecia compared to men with little or no alopecia.

However, [10] found that BMI did not differ between AGA cases and normal controls.

In our study, PLT count was found to lower in AGA patients compared to controls without significant difference. Current results were consistent with that of [11] who reported that platelets count in AGA patients $238.16 \pm$ $59.70 \times 103$ platelet $/ \mu \mathrm{L}$, that was lower than that in control group with $267.79 \pm 68.23 \times$ 103 platelet $/ \mu \mathrm{L}[\mathrm{P}$ value $<0.01]$. It is well accepted that platelets are necessary for normal hair growth and differentiation, the decrease in platelet count can be incriminated as an important factor causing or worsening AGA baldness.

This study showed that, AGA group showed significantly higher MPV when compared to control group $[\mathrm{p}<0.001$ for each].This disagrees with İslamoğlu and Demirbaş, [12] who found that the MPV values did not show any significant difference between the two groups.

In our study, NLR and PLR were found to be significantly higher in AGA patients compared to controls.

A factor suggested to mediate hair fall is an increased autoimmune reaction against hair follicles. This hypothetical mechanism was confirmed by a significant increase in WBC count and lymphocyte percent in contrast to other WBC cells. This allergic reaction could be mediated by proinflammatory effects of prostaglandin D2 released by WBC cells like lymphocytes with inhibitory effects on hair growth in AGA patients [13].

\section{Conclusion}

Patients with AGA showed significantly higher NLR, PLR and MPV when compared to control group.

\section{References}

[1] U.B.Peytavi, A.Blumeyer, A.Tosti, S1 guideline for diagnostic evaluation in androgenetic alopecia in men, women and adolescents. Br J Dermatol, Vol.164, pp.5-15,2011.

[2] D.M.Elhabak and W.A.Abdel Halim,YKL-40 A Sensitive Biomarker for Early Androgenetic Alopecia and Early Hidden Metabolic Syndrome. International journal of trichology, Vol.12 (2), pp. 49-55,2020.

[3] J.J.Hoffmann, K.C.Nabbe and N.M.Van den Broek, Effect of age and gender on reference intervals of red blood cell distribution width [RDW] and mean red cell volume [MCV]. Clin Chem Lab Med, Vol. 53(12), pp.2015-2019,2015.

[4] A.Asahina, N.Kubo, Y.Umezawa, Neutrophil-lymphocyte ratio, plateletlymphocyte ratio and mean platelet volume in Japanese patients with psoriasis and psoriatic arthritis: Response to therapy with biologics. J Dermatol, Vol.44 (10), pp.1112- 1121,2017.

[5] J.A.Leithead, N.Rajoriya, B.K.Gunson, Neutrophil to lymphocyte ratio predicts mortality in patients listed for liver transplantation. Liver Int, Vol.35, pp.502$509,2015$.

[6] K.Kridin, W.Shihade and S.ZelberSagi,Mean platelet volume in pemphigus vulgaris. Angiology, Vol.69 (4), pp.303307,2018.

[7] H.S.Banger, S.K.Malhotra, S.Singh, Is early onset androgenic alopecia a marker of metabolic syndrome and carotid artery atherosclerosis in young Indian male patients? Int J Trichology, Vol.7, pp.1417,2015.

[8] K.C.Dharam Kumar, Y.H.Kishan Kumar and V.Neladimmanahally,Association of Androgenetic Alopecia with Metabolic Syndrome: A Case-control Study on 100 Patients in a Tertiary Care Hospital in South India. Indian J Endocrinol Meta, Vol.22 (2), pp.196-199,2018.

[9] H.Gopinath and G.M.Upadya,Metabolic syndrome in androgenic alopecia. Indian J Dermatol Venereol Leprol, Vol.82 (4), pp.404-408,2016.

[10]C.Mumcuoglu, T.R.Ekmekci and S.Ucak, The investigation of insulin resistance and metabolic syndrome in male patients with early-onset androgenetic alopecia. Eur J Dermatol, Vol. 21, pp.79-82,2011.

[11]M.R.Dayer, F.Dehghani, D.Daer , Androgenetic Alopecia: A Chronic or Pubertal Onset Disease Retarded by Blood Donation. Zahedan J Res Med Sci, Vol.19(9), pp.e10074,2017.

[12]Z.G.K.İslamoğlu and A.Demirbaş ,Evaluation of complete blood cell and 
inflammatory parameters in patients with alopecia areata: Their association with disease severity. J Cosmet Dermatol, Vol.19(5), pp.1239-1245,2019.
[13] L.A.Garza, Y.Liu，Z.Yang,Prostaglandin D2 inhibits hair growth and is elevated in bald scalp of men with androgenetic alopecia. Sci Transl Med, Vol. 4 (126), pp. 126-34,2012. 